\title{
Invasive and drug resistant expression profile of different morphological structures of breast tumors
}

\author{
E. V. DENISOV ${ }^{1,2, *}$, T. S. GERASHCHENKO ${ }^{1,2}$, M. V. ZAVYALOVA ${ }^{2,3,4}$, N. V. LITVIAKOV ${ }^{1,2}$, M. M. TSYGANOV ${ }^{1,2}$, E. V. KAIGORODOVA ${ }^{2,3}$, \\ E. M. SLONIMSKAYA ${ }^{5,6}$, J. KZHYSHKOWSKA ${ }^{2,7}$, N. V. CHERDYNTSEVA ${ }^{1,2,6}$, V. M. PERELMUTER ${ }^{3,4}$
}

\begin{abstract}
${ }^{1}$ Laboratory of Molecular Oncology and Immunology, Tomsk Cancer Research Institute, Tomsk, Russian Federation; ${ }^{2}$ Laboratory of Translational Cell and Molecular Biomedicine, Tomsk State University, Tomsk, Russian Federation; ${ }^{3}$ Department of Pathological Anatomy and Cytology, Tomsk Cancer Research Institute, Tomsk, Russian Federation; ${ }^{4}$ Department of Pathological Anatomy, Siberian State Medical University, Tomsk, Russian Federation; ${ }^{5}$ Department of General Oncology, Tomsk Cancer Research Institute, Tomsk, Russian Federation; ${ }^{6}$ Department of Oncology, Siberian State Medical University; ${ }^{7}$ Department of Innate Immunity and Tolerance, Institute of Transfusion Medicine and Immunology, Medical Faculty Mannheim, University of Heidelberg, Mannheim, Germany
\end{abstract}

*Correspondence: d_evgeniy@oncology.tomsk.ru

\section{Received June 8, 2014 / Accepted November 10, 2014}

\begin{abstract}
In order to understand invasive/adhesive and drug resistant properties of intratumor morphological heterogeneity of breast cancer, we compared the expression of genes responsible for the cell adhesion and for the drug resistance between distinct morphological structures of breast tumors. Tubular (hollow-like), alveolar (morula-like), trabecular, solid structures/patterns, and discrete (small) groups of tumor cells were isolated from invasive carcinoma of no special type $(n=3)$ and invasive micropapillary carcinoma $(n=1)$ of the breast using laser microdissection. The gene expression of cadherins, catenins, integrins, ABC transporters, GSTP1, and drug targets was analyzed using qRT-PCR. Expression of catenin genes was identified in almost all structures. In contrast, the expression of cadherin and integrin genes significantly varied depending on the morphological variant. Cadherin expression declined in the row: solid - alveolar and trabecular structures - discrete groups of tumor cells. Expression of integrins declined in the row: solid and alveolar - trabecular structures - discrete groups of tumor cells. For drug resistance genes, trabecular structures more often demonstrated activity of genes coding for ABC transporters compared to other morphological variants. These results indicate that intratumoral morphological heterogeneity in breast cancer correlates with expression profile of adhesion and drug resistance genes reflecting different patterns of invasive growth and responsiveness to chemotherapy.
\end{abstract}

Key words: breast neoplasms, neoplasm invasiveness, cell adhesion, drug resistance, ATP-binding cassette transporters

Different tumors demonstrate the diversity of variants of invasive growth and of cell movement types. Tumor cells can migrate either as single cells or collectively as a group using mesenchymal, amoeboid, and amoeboid-filopodial motion $[1,2]$. The diversity of invasive growth patterns of tumor cells probably resulted in high intratumor morphological heterogeneity, which (e.g. in breast cancer) is represented by different morphological structures: tubular (hollow-like), alveolar (morula-like), trabecular, solid structures (patterns), and discrete (small) groups of tumor cells [3,4].

The diversity of invasive unit in different cancers is believed to be related with activity of cell-cell and cell-matrix adhesion molecules [5]. Decrease or loss of cell-cell junctions and turnover of cell-substrate adhesions was shown to correlate with the invasive phenotype and efficiency of metastasis of many tumors
[2]. In contrast, increased cell-cell and cell-matrix interactions were suggested to be associated with the development of the multicellular resistance, which is typical for tumor spheroids and clusters of different cultured tumor cell line types [6]. Intratumor morphological heterogeneity was shown to be related to lymph node metastasis and chemotherapy efficiency of invasive carcinoma of no special type (IC NST) [7-9] and invasive micropapillary carcinoma (IMPC) of the breast $[10,11]$. In spite of some studies clarifying the nature of the contribution of morphological heterogeneity to therapy responsiveness and metastasis of breast cancer $[7,10,11]$, the mechanisms of the above-mentioned associations remain to be identified.

In this study, we aimed to clarify whether different morphological structures of breast tumors have distinct adhesive/ migratory and drug resistant properties, and identified changes 

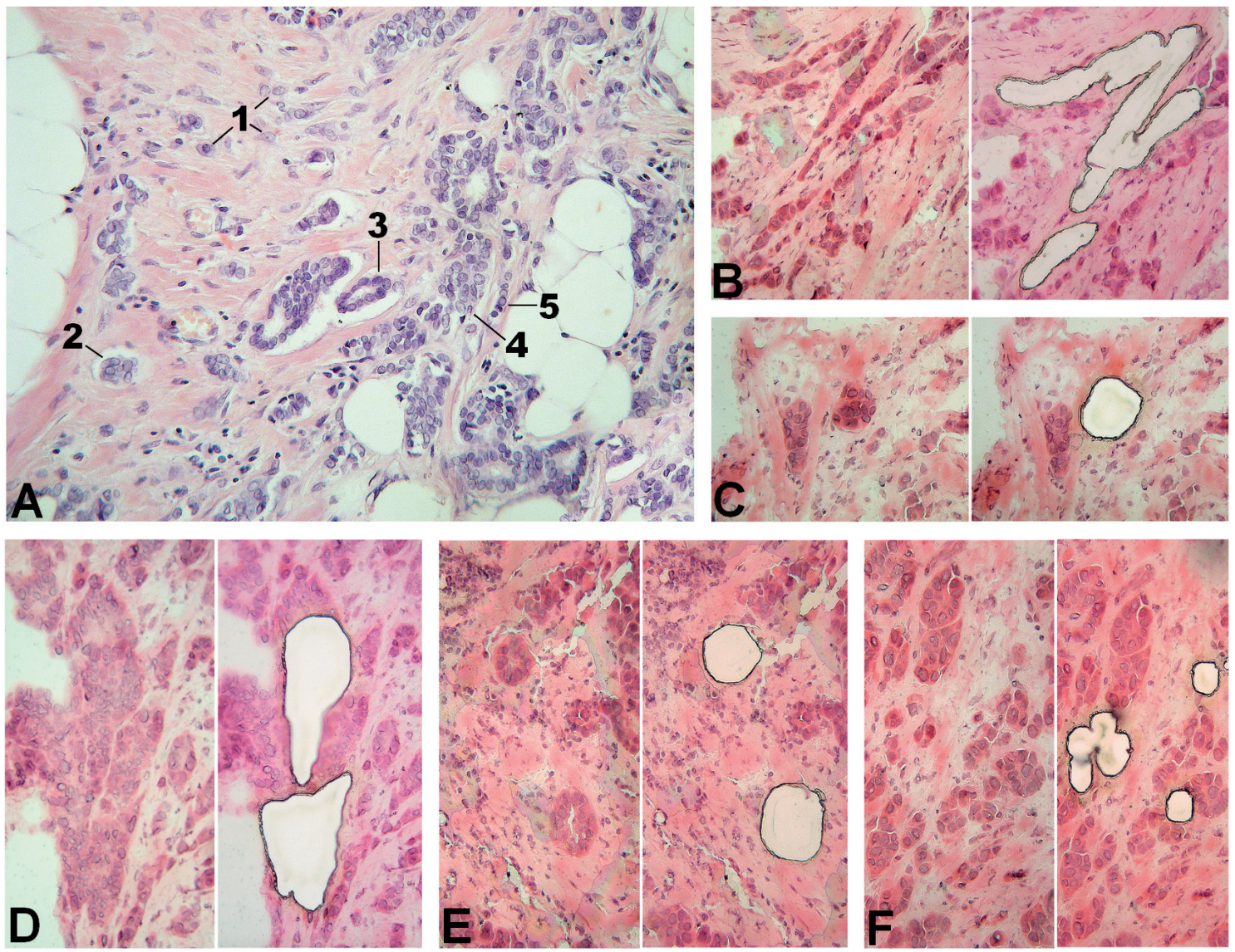

Figure 1. Different morphological structures of breast tumors. (A): Tumor section with discrete groups of tumor cells (1), alveolar (2), tubular (3), solid (4), and trabecular (5) structures. B-F: Tumor sections before and after laser microdissection of trabecular, alveolar, solid, tubular structures, and discrete groups of tumor cells, respectively. Tumor sections were stained by hematoxylin and eosin (200x magnification).

in the expression profile of genes responsible for cell-cell and cellmatrix interaction and for the drug resistance between different morphological structures in IC NST and in IMPC. The first group included cadherins ( $\mathrm{CDH} 1, \mathrm{CDH} 2$, and $\mathrm{CDH} 3)$, catenins $(C T N-$ NA1, CTNNB1), and integrins - ITGA6, ITGAV, ITGB1, ITGB3, and ITGB4, which were previously described to be involved in breast cancer progression [12]. The second group included drug resistance genes: $\mathrm{ABC}$ transporter genes $(A B C B 1, T A P 2, A B C C 1$, $A B C C 3, A B C C 5, A B C G 1$, and $A B C G 2)$, glutathione S-transferase gene (GSTP1), involved in detoxification of tumor cells from xenobiotics, and drug target genes - TOP1, TOP2A, TYMS, and TUBB3. We found that intratumoral morphological heterogeneity in breast cancer correlates with expression profile of adhesion and drug resistance genes. This finding is an important step to our understanding of the invasive, metastatic and chemoresistance nature of different morphological structures of breast tumors.

\section{Patients and methods}

Patients and tumors. Four patients with breast cancer diagnosed in the Cancer Research Institute (Tomsk, Russia) between 2012 and 2013 were included: patient \#1 (61 years old, IC NST, luminal A, T2NxMx, grade 2), patient \#2 (61 yr old, IC NST, luminal A, T2NxMx, grade 2), patient \#3 (49 yr old, IC NST, luminal A, T1NxMx, grade 2), and patient \#4 (56 yr old, IMPC, luminal B, T2N1M0). All cases were without any preoperative therapy. The surgery samples were first frozen by placing in liquid nitrogen, and stored at $-80^{\circ} \mathrm{C}$ until laser microdissection. The procedures followed in this study were in accordance with the Helsinki Declaration (1964, amended in 1975 and 1983). This study was approved by the institutional (Cancer Research Institute, SB RAMS) review board, all patients signed an informed consent for voluntary participation, and the number of ethical approval was 10 (29 September 2011).

Laser microdissection. Tubular (hollow-like), alveolar (morula-like), solid, trabecular structures, and discrete (small) groups of tumor cells (150-200 samples of each morphological structure, Fig. 1) were isolated from five $\mu \mathrm{m}$-thick hematoxylin \& eosin stained sections of frozen tumor samples using PALM MicroBeam laser capture microdissection (Carl Zeiss, Germany) as previously described [7]. About 150-200 

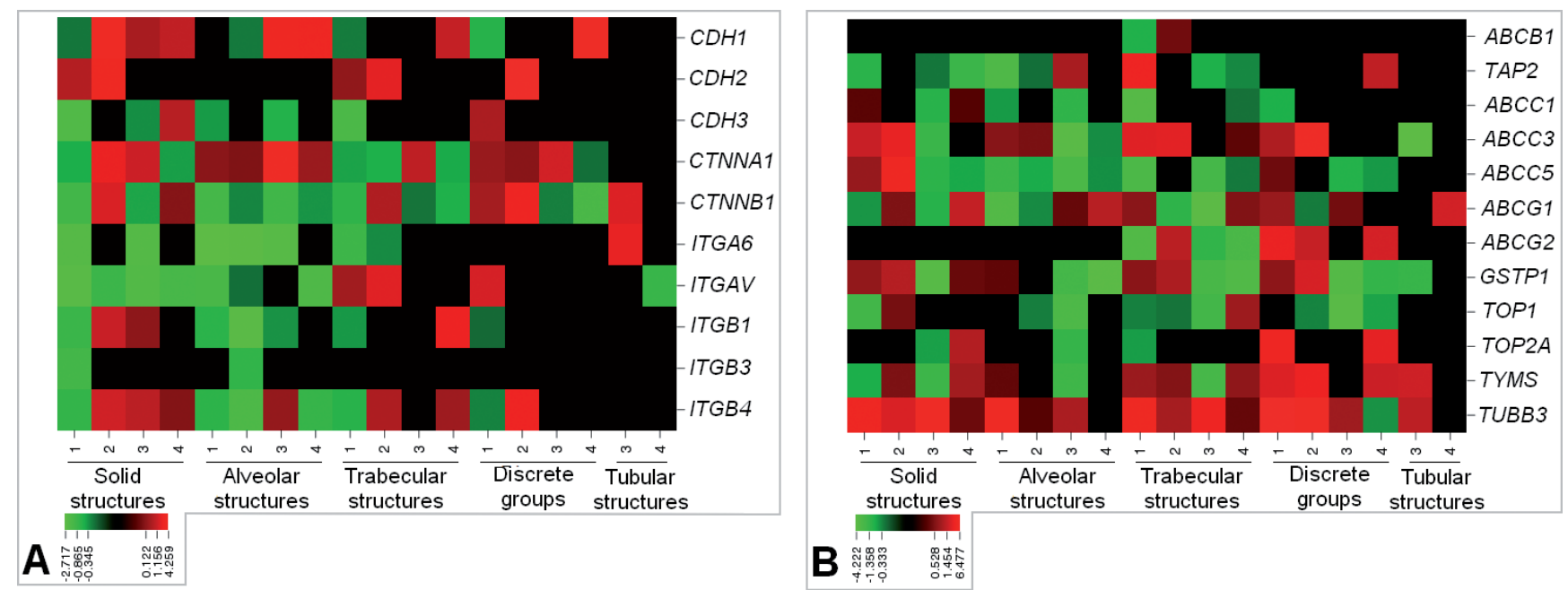

Figure 2. Heat map of expression levels of cell adhesion (A) and drug resistance genes (B) in different morphological structures of breast tumors. IC NST cases are shown as 1, 2, and 3; IMPC case - as 4 .

microdissected samples of each morphological structure were obtained from each breast tumor.

RNA isolation and cDNA synthesis. The microdissected material was collected in RLT lysis buffer (RNeasy Plus Micro Kit, Qiagen, USA), and total RNA was extracted according to the manufacturer's instructions. Ribolock RNase inhibitor (Fermentas, Lithuania) was added to the isolated RNA. RNA quality was assessed by RIN using 2200 TapeStation Instrument and High Sensitivity R6K ScreenTape (Agilent
Technologies, Inc., Santa Clara, USA). RIN varied from 4.0 to 8.1 (average 6.8 ). Reverse transcription, ligation, and whole transcriptome amplification were performed using the QuantiTect Whole Transcriptome Kit (Qiagen, USA) according to the manufacturer's instructions.

Expression analysis. qRT-PCR for measurement of the gene expression levels was performed as previously described [7]. The list of genes, primers and probe sequences are given in Supplementary Table 1 . The expression levels were presented
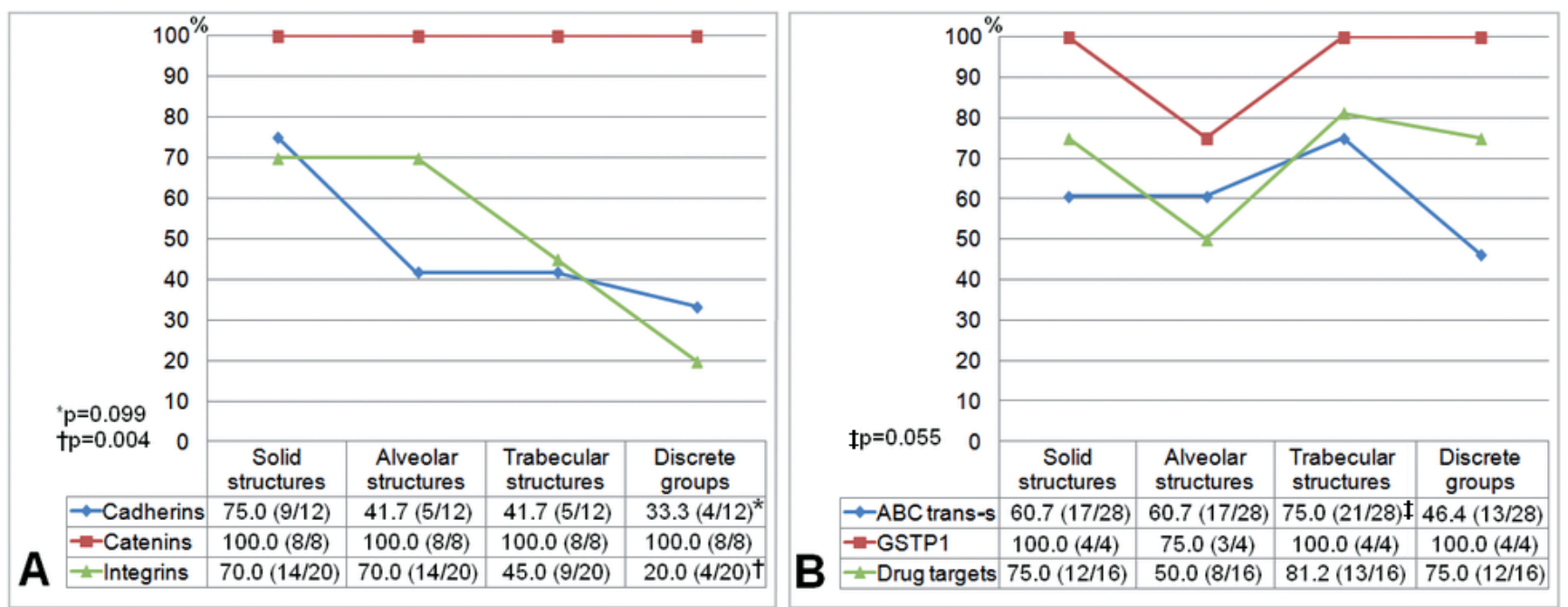

Figure 3. Activity of cell adhesion (A) and drug resistance (B) genes in different morphological structures of breast tumors. Activity was calculated as the number of cases displaying gene expression in certain structure divided by the maximally possible number of cases with gene expression in the same structure. For example, $75 \%$ activity of cadherin genes in solid structures means that among maximally possible number of cases ( $\mathrm{n}=12$ ) with gene expression, only 9 cases showed gene expression. ${ }^{*} p=0.099$ : differences between discrete groups of tumor cells and solid structures; $\dagger p=0.004$ : differences between discrete groups of tumor cells and solid / alveolar structures; $\$ \mathrm{p}=0.055$ : differences between trabecular structures and discrete groups of tumor cells. Only two cases (\#1 and \#2) contained tubular structures in breast tumors. 

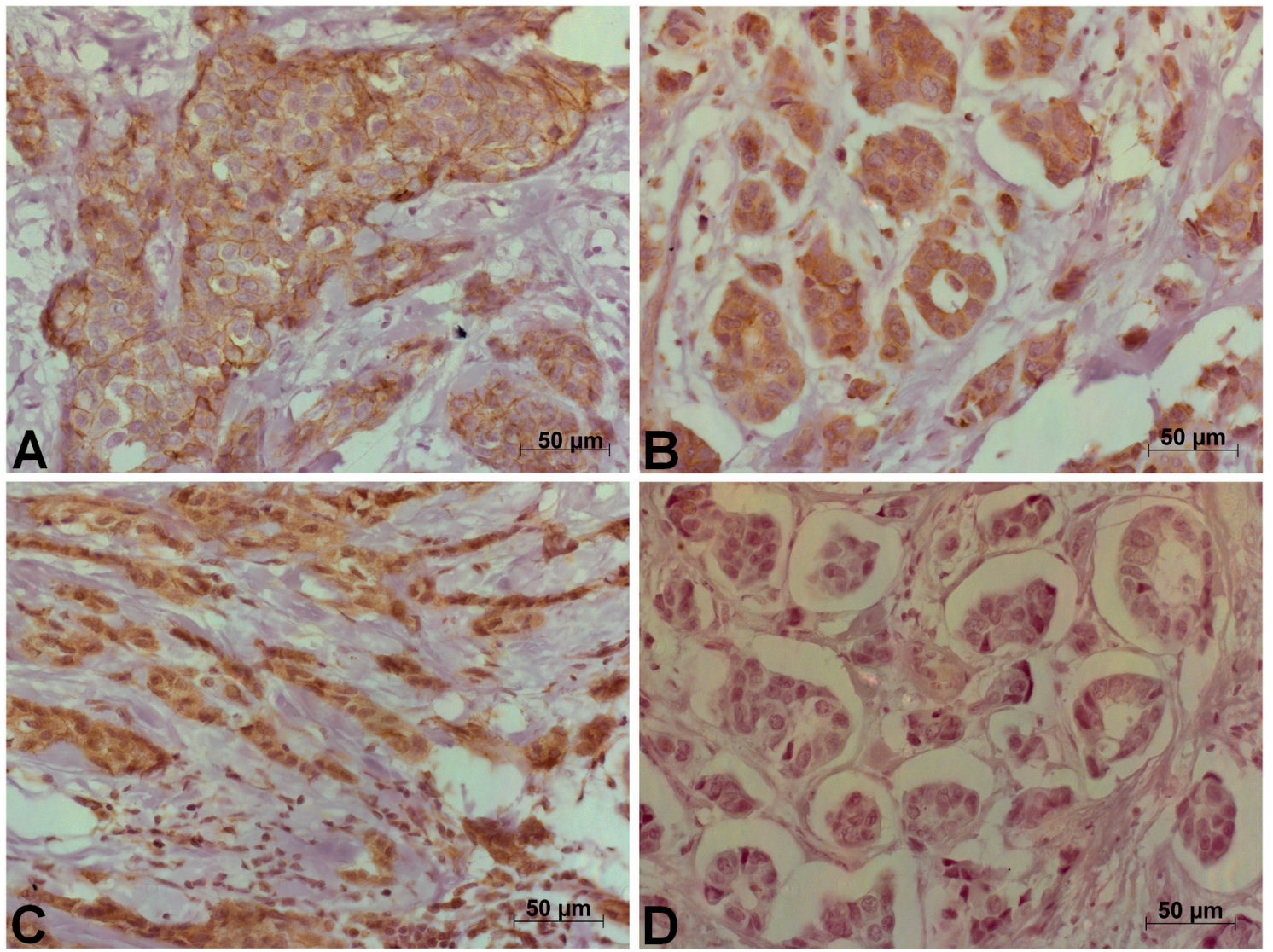

Figure 4. Immunohistochemistry analysis of CDH1, ABCG1, ABCG2, and ABCB1 expression in different morphological structures of breast tumors. (A): Membrane expression of CDH1 (E-cadherin) in tumor cells of solid structure. (B): Cytoplasmic expression of ABCG1 in tumor cells of alveolar and tubular structures. (C): Cytoplasmic and nuclear expression of ABCG2 (BCRP) in tumor cells of trabecular structures. (D): The absence of expression of ABCB1 (P-glycoprotein) in tumor cells of alveolar and tubular structures. Scale bar 50 microns.

as $\mathrm{n}$-fold differences in the target gene expression relative to $A C T B 1$ and normal breast tissue (Supplementary Tables 2 and 3). A heat map (Fig. 2A,B) to visualize results was constructed based on the log-transformed expression levels using CIMminer software (http://discover.nci.nih.gov/cimminer/) [13]. After $\log$ transformation, the low expression levels (up to 1) had negative values, whereas the high expression levels (more than 1) - positive numbers. qRT-PCR analysis was conducted with reference to the Minimum Information for Publication of Quantitative Real-time PCR experiments (MIQE) guidelines [14].

The expression of some genes (CDH1, ABCB1, ABCG1, and $A B C G 2$ ) was validated at the protein level using immunohistochemistry (IHC). The following antibodies were used: E-cadherin (CDH1, 36B5 clone, 1:30 dilution, Dako), P-glycoprotein (ABCB1, JSB-1 clone, 1:40 dilution, Abcam), ABCG1 (EP1366Y clone, 1:50 dilution, Abcam), and BCRP (ABCG2, BXP-53 clone, 1:20 dilution, Abcam). The results of IHC was assessed as the percentage of positively stained cells with any degree of positive marker expression in different parts of section (1000 cells in 10 fields of view, 400x magnification), corresponding to different morphological structures (Fig. 4).

Statistics. Pearson's chi-square test $(2 \times 2$ table) was used to identify the significance of differences in expression of cell adhesion and drug resistance genes between different morphological structures of breast tumors. Yates' corrected chi-square test (when expected frequencies of less than 10 were found) [15] and Fisher's exact test (when expected frequencies of less than 6 were found) [16] were also utilized. Differences were considered as significant if the corrected $p$ value was less than 0.05 . All $\mathrm{p}$ values were two-sided.

\section{Results}

Expression of cell adhesion genes in different morphological structures of breast tumors. First, we showed differences in expression of genes responsible for the cell adhesion -cadherins $(\mathrm{CDH} 1, \mathrm{CDH} 2$, and $\mathrm{CDH} 3)$, catenins (CTNNA1, CTNNB1), and integrins - ITGA6, ITGAV, ITGB1, ITGB3, and ITGB4 between different morphological structures of four breast tumors (Fig. 2A, 3A). Expression of catenin 
genes (CTNNA1 and CTNNB1) was presented in almost all structures. However, the expression level varied from sample to sample. The expression levels of cadherin and integrin genes differed significantly between morphological variants (Fig. 2A). Overall, activity of cadherin genes was decreasing in the row: solid structures (75.0\%) - alveolar and trabecular structures $(41.7 \%)$ - discrete groups of tumor cells (33.3\%). Whereas the activity of integrin genes was decreasing in the row: solid and alveolar structures (70.0\%) - trabecular structures (45.0\%) - discrete groups of tumor cells (20.0\%; Fig. 3A). The differences were statistically significant for the activity of integrin genes when the discrete groups of tumor cells were compared to the solid/alveolar structures ( $\mathrm{p}=0.004$; Fig. $3 \mathrm{~A}$ ). The tendency towards a decrease in the cadherin activity was found between discrete groups of tumor cells and solid structures ( $\mathrm{p}=0.099$; Fig. 3A). In tubular structures, the expression of almost all cell adhesion genes (excepting CTNNB1, ITGA6, and $I T G A V$ ) was not detectable (Fig. 2A). It was an unexpected result since presence of tubular structures in breast tumors is directly proportional to tumor differentiation and inversely proportional to tumor grade [17].

Expression of drug resistance genes in different morphological structures of breast tumors. Second, we demonstrated the differences in activity of drug resistance genes - $A B C$ transporter genes ( $A B C B 1, T A P 2, A B C C 1, A B C C 3, A B C C 5$, $A B C G 1$, and $A B C G 2$ ), glutathione S-transferase gene (GSTP1), and drug target genes - TOP1, TOP2A, TYMS, and TUBB3 between different morphological structures of breast tumors (Fig. 2B, 3B). Expression of $\mathrm{ABC}$ transporter genes was found to be more frequent in trabecular structures compared to other morphological variants ( $75.0 \%$ vs. $46.4 \%-60.7 \%$, Fig. $3 \mathrm{~B}$ ). However, the differences were significant only in comparison with discrete groups of tumor cells ( $\mathrm{p}=0.055$; Fig. 3B). Expression of the $A B C B 1$ gene was found only in trabecular structures (Fig. 2B). In addition, only trabecular structures and discrete groups of tumor cells showed ABCG2 expression (Fig. 2B). Moreover, expression of drug target genes was more often detected in trabecular, solid structures, and discrete groups of tumor cells than in alveolar structures $(75.0 \%-81.2 \%$ vs. $50.0 \%$, Fig. 3B), however the differences have not reached the statistical significance $(\mathrm{p}>0.05)$. Almost all structures demonstrated expression ABCG1, GSTP1, and TUBB3 genes, while TUBB3 activity was the highest among the studied genes (Fig. 2B). Another drug target gene - TYMS was also overexpressed in the most structures, whereas TOP1 expression was mainly downregulated (Fig. 2B).

Immunohistochemical validation of gene expression data. Finally, we evaluated expression of some genes $(C D H 1$, $A B C B 1, A B C G 1$, and $A B C G 2)$ by immunohistochemistry (Fig. 4). For each gene, there were concordant cases which were regarded as being negative/positive by both methods and discordant cases when protein expression was positive by IHC, but was described as being negative by qRT-PCR and vice versa (Supplementary Table 4). For instance, the absence of $A B C B 1$ gene expression in different morphological structures correlated with the lack of protein expression. The exception was two cases with trabecular structures in which $\mathrm{ABCB} 1$ expression was regarded as being positive by qRTPCR but negative by IHC. The expression of the ABCG1 gene, which was positive in almost all structures, was confirmed on the protein level. The exception was one case with discrete groups of tumor cells and one case with tubular structures, which displayed ABCG1 expression on the protein level, but not on the mRNA level. For CDH1 and ABCG2, discordance between mRNA and protein levels was shown in 7 and in 11 cases, respectively.

\section{Discussion}

Tumor invasion and drug resistance are key processes that define an outcome for a cancer patient and that require reliable therapeutic targeting. Currently, knowledge about molecular signatures of patterns of invasive growth in cancer is limited. It was suggested that the collective cell invasion is presumably characterized by the increased intercellular and extracellular matrix adhesion, while migration in the form of single cells and small multicellular aggregations may lose cell-cell interaction and may had less cell-matrix junctions depending on movement type - amoeboid, mesenchymal or amoeboid-filopodial $[1,2]$.

Based on our data and the previous suggestions [2], we concluded that solid, alveolar, and trabecular structures of breast tumors reflect the collective cell migration, whereas discrete groups of tumor cells may represent single-cell migration and multicellular streaming. Discrete groups of tumor cells comprise heterogeneous morphological variants including both single cells and small aggregations of up to five tumor cells. In particular, these structures from some breast tumors demonstrate the expression of cadherin genes, namely CDH1 (Fig. 2A), that seems to be specific for cell-cell junctions in small tumor clusters, but not for the single tumor cells. The discrete groups of tumor cells showed the lowest activity of integrin genes, while the expression of these genes was completely absent in this morphological variant of two breast cancer cases (Fig. 2A). The latter observation provides the argument for the prevalence of cells with amoeboid phenotype in discrete groups of tumor cells, because it is known that amoeboid cells lack matrix adhesion and move via formation of multiple blebs or actin-enriched leading edge $[1,2]$. It is interesting to note that some morphological structures, namely solid structures, displayed coexpression of $\mathrm{CDH} 1$ and $\mathrm{CDH} 2 / \mathrm{CDH} 3$ genes. Although, it is well known that expression of these genes is mutually exclusive, and the loss of $\mathrm{CDH} 1$ (E-cadherin) expression is related to upregulation of $\mathrm{CDH} 2$ (N-cadherin) and $\mathrm{CDH} 3$ (P-cadherin) in epithelialto-mesenchymal transition (EMT) [18]. Our data can be explained by the presence of transitional cell states in EMT, when $\mathrm{CDH} 1$ and $\mathrm{CDH} 2 / \mathrm{CDH} 3$ genes are coexpressed [19], and by the presence of EMT in not all tumor cells of any type of morphological structures. 
The resistance of cancer to chemotherapy is driven by drug efflux pumps (ABC transporters) and depends on the presence of drug targets $[20,21] . A B C B 1$ and $A B C G 2$ genes encode key ABC-transporters - P-glycoprotein and breast cancer resistance protein, respectively, acting as broad-spectrum drug efflux pumps and play the major role in drug resistance [20]. Moreover, $A B C B 1$ and $A B C G 2$ genes are consistently expressed in stem cells including cancer stem cells and in tumor cells undergoing EMT, and are related to invasive and metastatic behavior [20,22]. Taking into account that $A B C B 1$ and $A B C G 2$ genes were found by us to be expressed only in trabecular structures, it is most likely that tumor cells within this morphological variant display stemness and/or EMT features and possess increased invasive potential. The latter suggestion may be also relevant to the discrete groups of tumor cells because these morphological structures showed also expression of the $A B C G 2$ gene. The high invasive behavior of trabecular structures and discrete groups of tumor cells was also confirmed by a decreased $\mathrm{CDH} 1$ and integrin activity in these morphological variants (Fig. 2A, 3A).

The expression of some genes (CDH1, $A B C B 1, A B C G 1$, and $A B C G 2)$ was evaluated by immunohistochemistry. $A B C B 1$ and $A B C G 1$ gene expression was confirmed at the protein level, whereas changes in expression level of $C D H 1$ and $A B C G 2$ genes did not correlate with protein expression in many cases. Discordances between mRNA and protein levels may be result of the presence of different regulatory components in transcription, translation etc. Previously, it was well shown that only $\sim 40 \%$ of the changes in protein expression correlate with mRNA level, whereas remaining $\sim 60 \%$ of the protein expression variation can be explained both by the transcriptional and post-transcriptional regulation and by transcript/ protein degradation [23]. Moreover, single studies reported cases which were positive by IHC but were regarded as being negative by qRT-PCR [24, 25].

In summary, we suggest that intratumoral morphological heterogeneity in breast cancer reflects different patterns of tumor invasive growth. Distinct morphological structures of breast tumors demonstrate specific expression profile of cellcell (cadherins) and cell-matrix (integrins) adhesion genes. We also demonstrated specific activation of drug resistance genes in different morphological structures suggesting the dependence of chemotherapy efficiency on the intratumoral morphological heterogeneity. Indeed, our previous studies demonstrated that breast tumors with trabecular and alveolar structures show weak response to neoadjuvant chemotherapy $[7,26]$. However, according to our recent data [7] and the results of the current study, an increased expression of drug resistance genes is observed in trabecular structures, but not in alveolar morphological variant. In order to identify molecular mechanism of the chemotherapy resistance of the alveolar structures, and to understand the invasive profile of intratumoral morphological heterogeneity, further studies are required applying wholetranscriptome and genome profiling of tumor cells within different morphological structures of breast tumors.
Supplementary information is available in the online version of the paper.

Acknowledgements: The study was supported by the Russian Scientific Foundation, grant \#14-15-00318 (sample collection, laser microdissection, and genetic part of the study) and grant \#14-1500350 (immunohistochemical part of the study). We acknowledge support of this work by the Tomsk State University Competitiveness Improvement Program.

\section{References}

[1] CHIKINA AS, ALEXANDROVA AY. The cellular mechanisms and regulation of metastasis formation. Molecular Biology 2014; 48: 165-180. http://dx.doi.org/10.1134/ $\underline{\text { S0026893314020046 }}$

[2] FRIEDL P, ALEXANDER S. Cancer invasion and the microenvironment: plasticity and reciprocity. Cell 2011; 147: 992-1009. http://dx.doi.org/10.1016/j.cell.2011.11.016

[3] GERASHCHENKO TS, DENISOV EV, LITVIAKOV NV, ZAVYALOVA MV, VTORUSHIN SV, et al. Intratumor heterogeneity: nature and biological significance. Biochemistry (Mosc) 2013; 78: 1201-1215. http://dx.doi.org/10.1134/ $\underline{\text { S0006297913110011 }}$

[4] LAKHANI SR, ELLIS IO, SCHNITT SJ, TAN PH, VAN DE VIJVER MJ. World Health Organization (WHO) classification of tumours of the breast, 4th edn. Lyon: IARC Press. 2012.

[5] FRIEDL P, LOCKER J, SAHAI E, SEGALL JE. Classifying collective cancer cell invasion. Nat Cell Biol 2012; 14: 777-783. http://dx.doi.org/10.1038/ncb2548

[6] IVASCU A, KUBBIES M. Diversity of cell-mediated adhesions in breast cancer spheroids. Int J Oncol 2007; 31: 1403-1413.

[7] DENISOV EV, LITVIAKOV NV, ZAVYALOVA MV, PERELMUTER VM, VTORUSHIN SV, et al. Intratumoral morphological heterogeneity of breast cancer: neoadjuvant chemotherapy efficiency and multidrug resistance gene expression. Sci Rep 2014; 4: 4709. http://dx.doi.org/10.1038/ $\underline{\text { srep04709 }}$

[8] ZAVYALOVA MV, PERELMUTER VM, VTORUSHIN SV, DENISOV EV, LITVYAKOV NV, et al. The presence of alveolar structures in invasive ductal NOS breast carcinoma is associated with lymph node metastasis. Diagn Cytopathol 2013; 41: 279-282. http://dx.doi.org/10.1002/dc.21852

[9] ZAVYALOVA MV, DENISOV EV, TASHIREVA LA, GERASHCHENKO TS, LITVIAKOV NV, et al. Phenotypic drift as a cause for intratumoral morphological heterogeneity of invasive ductal breast carcinoma not otherwise specified. BioResearch Open Access 2013; 2: 148-154. http://dx.doi. org/10.1089/biores.2012.0278

[10] DOUBLIER S, BELISARIO DC, POLIMENI M, ANNARATONE L, RIGANTI C, et al. HIF-1 activation induces doxorubicin resistance in MCF7 3-D spheroids via P-glycoprotein expression: a potential model of the chemo-resistance of invasive micropapillary carcinoma of the breast. BMC Cancer 2012; 12: 4. http://dx.doi.org/10.1186/1471-2407-12-4 
[11] GUO X, CHEN L, LANG R, FAN Y, ZHANG X, et al. Invasive micropapillary carcinoma of the breast: association of pathologic features with lymph node metastasis. Am J Clin Pathol 2006; 126: 740-746. http://dx.doi.org/10.1309/ AXYY4AJTMNW6FRMW

[12] DESGROSELLIER JS, CHERESH DA. Integrins in cancer: biological implications and therapeutic opportunities. Nat Rev Cancer 2010; 10: 9-22. http://dx.doi.org/10.1038/ $\underline{\operatorname{nrc} 2748}$

[13] WEINSTEIN JN, MYERS TG, O‘CONNOR PM, FRIEND SH, FORNACE AJ, JR., et al. An information-intensive approach to the molecular pharmacology of cancer. Science 1997; 275: 343-349. http://dx.doi.org/10.1126/ science. 275.5298 .343

[14] BUSTIN SA, BENES V, GARSON JA, HELLEMANS J, HUGGETT J, et al. The MIQE guidelines: minimum information for publication of quantitative real-time PCR experiments. Clin Chem 2009; 55: 611-622. http://dx.doi.org/10.1373/ clinchem.2008.112797

[15] BROWN JD. Yates correction factor. Shiken: JALT Testing \& Evaluation SIG Newsletter 2004; 8: 22-27.

[16] MOTULSKY H. Intuitive Biostatistics. New York: Oxford University Press, 1995.

[17] ELSTON CW, ELLIS IO. Pathological prognostic factors in breast cancer. I. The value of histological grade in breast cancer: experience from a large study with long-term follow-up. Histopathology 1991; 19: 403-410. http://dx.doi.org/10.1111/ j.1365-2559.1991.tb00229.x

[18] WHEELOCK MJ, SHINTANI Y, MAEDA M, FUKUMOTO Y, JOHNSON KR. Cadherin switching. J Cell Sci 2008; 121: 727-735. http://dx.doi.org/10.1242/jcs.000455

[19] ARMSTRONG AJ, MARENGO MS, OLTEAN S, KEMENY G, BITTING RL, et al. Circulating tumor cells from patients with advanced prostate and breast cancer display both epithelial and mesenchymal markers. Mol Cancer Res 2011; 9:
997-1007. http://dx.doi.org/10.1158/1541-7786.MCR-10$\underline{0490}$

[20] STAVROVSKAYA AA, STROMSKAYA TP. Transport proteins of the ABC family and multidrug resistance of tumor cells. Biochemistry (Mosc) 2008; 73: 592-604. http://dx.doi. org/10.1134/S0006297908050118

[21] COLEY HM. Mechanisms and consequences of chemotherapy resistance in breast cancer European Journal of Cancer Supplements 2009; 7: 3-7. http://dx.doi.org/10.1016/S13596349(09)70003-5

[22] MALLINI P, LENNARD T, KIRBY J, MEESON A. Epithelialto-mesenchymal transition: what is the impact on breast cancer stem cells and drug resistance. Cancer Treat Rev 2014; 40: 341-348. http://dx.doi.org/10.1016/j.ctrv.2013.09.008

[23] VOGEL C, MARCOTTE EM. Insights into the regulation of protein abundance from proteomic and transcriptomic analyses. Nat Rev Genet 2012; 13: 227-232.

[24] KORDEK R, POTEMSKI P, KUSINSKA R, PLUCIENNIK E, BEDNAREK A. Basal keratin expression in breast cancer by quantification of mRNA and by immunohistochemistry. J Exp Clin Cancer Res 2010; 29: 39. http://dx.doi.org/10.1186/17569966-29-39

[25] BADVE SS, BAEHNER FL, GRAY RP, CHILDS BH, MADDALA T, et al. Estrogen- and progesterone-receptor status in ECOG 2197: comparison of immunohistochemistry by local and central laboratories and quantitative reverse transcription polymerase chain reaction by central laboratory. J Clin Oncol 2008; 26: 2473-2481. http://dx.doi.org/10.1200/ ICO.2007.13.6424

[26] ZAVYALOVA MV, LITVYAKOV NV, GARBUKOV EY, VTORUSHIN SV, STAKHEEVA MN, et al. Relationship between tumor sensitivity to neoadjuvant chemotherapy and histologic pattern of primary tumor in unicentric infiltrating ductal breast carcinoma. Siberian Journal of Oncology 2008; 6: $30-34$. 


\section{Supplementary Information}

\section{Invasive and drug resistant expression profile of different morphological structures of breast tumors}

E. V. DENISOV ${ }^{1,2, *}$, T. S. GERASHCHENKO ${ }^{1,2}$, M. V. ZAVYALOVA ${ }^{2,3,4}$, N. V. LITVIAKOV ${ }^{1,2}$, M. M. TSYGANOV ${ }^{1,2}$, E. V. KAIGORODOVA ${ }^{2,3}$, E. M. SLONIMSKAYA ${ }^{5,6}$, J. KZHYSHKOWSKA ${ }^{2,7}$, N. V. CHERDYNTSEVA ${ }^{1,2,6}$, V. M. PERELMUTER ${ }^{3,4}$

${ }^{1}$ Laboratory of Molecular Oncology and Immunology, Tomsk Cancer Research Institute, Tomsk, Russian Federation; ${ }^{2}$ Laboratory of Translational Cell and Molecular Biomedicine, Tomsk State University, Tomsk, Russian Federation; ${ }^{3}$ Department of Pathological Anatomy and Cytology, Tomsk Cancer Research Institute, Tomsk, Russian Federation; ${ }^{4}$ Department of Pathological Anatomy, Siberian State Medical University, Tomsk, Russian Federation; ${ }^{5}$ Department of General Oncology, Tomsk Cancer Research Institute, Tomsk, Russian Federation; ${ }^{6}$ Department of Oncology, Siberian State Medical University; ${ }^{7}$ Department of Innate Immunity and Tolerance, Institute of Transfusion Medicine and Immunology, Medical Faculty Mannheim, University of Heidelberg, Mannheim, GermanyCorrespondence: d_evgeniy@oncology.tomsk.ru

\section{Supplementary Tables}

Supplementary Table 1. The Target Genes and Primers/Probes Used in The Study

\begin{tabular}{|c|c|c|c|c|}
\hline $\begin{array}{c}\text { HGNC } \\
\text { Gene Names }\end{array}$ & Synonims & $\begin{array}{l}\text { Primer Sequence } \\
\quad\left(F, R, 5^{`} \rightarrow 3^{c}\right)\end{array}$ & $\begin{array}{l}\text { Probe Sequence } \\
\qquad\left(5^{`} \rightarrow 3^{`}\right)\end{array}$ & Design \\
\hline $\mathrm{CDH} 1$ & E cadherin & $\begin{array}{l}\text { aacgacccaacccaagaat } \\
\text { ccttcacagtcacacacgct }\end{array}$ & ataaccagaataaagaccaagtgacca & \multirow{10}{*}{ OrD } \\
\hline $\mathrm{CDH} 2$ & $\mathrm{~N}$ cadherin & $\begin{array}{c}\text { tgagcctgaagccaacct } \\
\text { gcttactgaattgtcttgggaa }\end{array}$ & gaggagtcagtgaaggagtcagca & \\
\hline $\mathrm{CDH} 3$ & P cadherin & $\begin{array}{l}\text { tggtgagaaagaagcggaa } \\
\text { tgtcatagtcctggtcctcttc }\end{array}$ & ccctcctactcccagaagatgaca & \\
\hline CTNNA1 & a catenin & $\begin{array}{l}\text { ggacgacagtggcaatgac } \\
\text { cttggcagcactgatgaca }\end{array}$ & atggagatgacagactttacccgagg & \\
\hline CTNNB1 & b catenin & $\begin{array}{l}\text { ggaatgaaggtgtggcga } \\
\text { ttcttgtaatcttgtggcttgtc }\end{array}$ & ctgctgttttgttccgaatgtctga & \\
\hline ITGA6 & a6 integrin & $\begin{array}{l}\text { tggctatgatgtggcggt } \\
\text { tcaaaatactgtggggctcc }\end{array}$ & tcaacaaggatgggtggcaaga & \\
\hline$I T G A V$ & $\alpha \mathrm{V}$ integrin & $\begin{array}{l}\text { atctaaatacgaccccaatgtt } \\
\text { aagtcatctatgccatcacca }\end{array}$ & tttgggttattctgtggctgtcgga & \\
\hline ITGB1 & $\beta 1$ integrin & $\begin{array}{r}\text { ttactcagatccaaccacagca } \\
\text { aaggtagtagaggtcaatgggat }\end{array}$ & taagatcaggggagccacagacatt & \\
\hline ITGB3 & $\beta 3$ integrin & $\begin{array}{l}\text { agaatgaggatgactgtgtcgt } \\
\text { gagagcaggaccaccagg }\end{array}$ & tagaagagccagagtgtcccaagg & \\
\hline ITGB4 & $\beta 4$ integrin & $\begin{array}{l}\text { gggagagcatcgtggtcat } \\
\text { tcaaaatgccgctcctca }\end{array}$ & acagaggagacccagattgacaccac & \\
\hline$A B C B 1$ & PGP/MDR1 & $\begin{array}{l}\text { gattgacagctacagcacgg } \\
\text { ggtcgggtgggatagttga }\end{array}$ & tgccgaacacattggaaggaaa & OrD \\
\hline TAP2 & ABCB3 & $\begin{array}{l}\text { ctggtcgtgtgattgacatcct } \\
\text { gcaagttgattcgagacatggt }\end{array}$ & aggtgattttgacccccatgccttt & Nishimura et al. 2002 \\
\hline$A B C C 1$ & MRP1 & $\begin{array}{l}\text { aggtgggctgcggaaag } \\
\text { cggagcccttgatagcca }\end{array}$ & tggctgagatggacaaagtggag & OrD \\
\hline$A B C C 3$ & MRP3 & $\begin{array}{l}\text { gcaccattgtcgtggctaca } \\
\text { gcaggacacccaggaccat }\end{array}$ & catcctctcccacctgtccaagctca & Steinbach et al. 2003 \\
\hline
\end{tabular}


Supplementary Table 1. (Continued)

\begin{tabular}{|c|c|c|c|c|}
\hline $\begin{array}{c}\text { HGNC } \\
\text { Gene Names }\end{array}$ & Synonims & $\begin{array}{l}\text { Primer Sequence } \\
\qquad\left(F, R, 5^{c} \rightarrow 3^{c}\right)\end{array}$ & $\begin{array}{l}\text { Probe Sequence } \\
\qquad\left(5^{\varsigma} \rightarrow 3^{c}\right)\end{array}$ & Design \\
\hline$A B C C 5$ & MRP5 & $\begin{array}{l}\text { caagagggtaaactggttgga } \\
\text { ctaaaatggctgaaatgagagag }\end{array}$ & ggcagtgtgggaagtggaaaa & OrD \\
\hline$A B C G 1$ & ABC8/White 1 & $\begin{array}{l}\text { cctactacctggccaagaccat } \\
\text { agtacacgatgctgcagtaggc }\end{array}$ & acgtgccctttcagatcatgttcccagt & Nishimura et al. 2002 \\
\hline$A B C G 2$ & BCRP & $\begin{array}{l}\text { aaaggatgtctaagcaggga } \\
\text { tgaggccaataaggtgagg }\end{array}$ & tcgaggctgatgaatggagaag & \multirow{2}{*}{ OrD } \\
\hline GSTP1 & $\begin{array}{l}\text { Glutathione } \\
\text { S-transferase } \\
\end{array}$ & $\begin{array}{l}\text { ctggtggacatggtgaatgac } \\
\text { cttgcccgcctcatagttg }\end{array}$ & aggacctccgctgcaaatacatctc & \\
\hline TOP1 & Topoisomerase (DNA) I & $\begin{array}{l}\text { ggcgagtgaatctaaggataatgaa } \\
\text { tggatatcttaaagggtacagcgaa }\end{array}$ & accattttcccatcatcctttgttctgagc & Yu et al. 2005 \\
\hline TOP2A & $\begin{array}{c}\text { Topoisomerase (DNA) } \\
\text { II alpha }\end{array}$ & $\begin{array}{l}\text { agtcgctttcagggttcttgag } \\
\text { tttcatttacaggctgcaatgg }\end{array}$ & cccttcacgaccgtcaccatgga & Zhou et al. 2002 \\
\hline TYMS & Thymidylate synthetase & $\begin{array}{l}\text { ctgtcctgccagctgtacca } \\
\text { gcgtagctggcgatgttga }\end{array}$ & ccgaggeccatgtctcccgat & Sowers et al. 2003 \\
\hline TUBB3 & Beta-tubulin class III & $\begin{array}{l}\text { gggccaagttctgggaagtc } \\
\text { cgagtcgcccacgtagttg }\end{array}$ & atgagcatggcatcgaccccagc & Lefever et al. 2009 \\
\hline
\end{tabular}

Abbreviations: HGNC, HUGO Gene Nomenclature Committee; F, forward; R, reverse primer; OrD, original design.

Supplementary Table 2. Expression levels of cell adhesion genes in different morphological structures of breast tumors $(n=4)$

\begin{tabular}{|c|c|c|c|c|c|c|c|c|c|c|c|}
\hline & Cases & $\mathrm{CDH} 1$ & $\mathrm{CDH} 2$ & $\mathrm{CDH} 3$ & CTNNA1 & CTNNB1 & ITGA6 & ITGAV & $I T G B 1$ & ITGB3 & ITGB4 \\
\hline \multirow{4}{*}{$\begin{array}{l}\text { Solid } \\
\text { structures }\end{array}$} & 1 & 0.74 & 6.18 & 0.03 & 0.27 & 0.10 & 0.02 & 0.01 & 0.14 & 0.009 & 0.18 \\
\hline & 2 & 617.25 & 175.72 & 0 & 51.12 & 28.23 & 0 & 0.14 & 14.33 & 0 & 23.48 \\
\hline & 3 & 3.75 & 0 & 0.54 & 17.29 & 0.37 & 0.02 & 0.02 & 1.39 & 0 & 11.35 \\
\hline & 4 & 13.19 & 0 & 11.12 & 0.38 & 1.13 & 0 & 0.08 & 0 & 0 & 1.03 \\
\hline \multirow{4}{*}{$\begin{array}{l}\text { Alveolar } \\
\text { structures }\end{array}$} & 1 & 0 & 0 & 0.45 & 1.33 & 0.08 & 0.002 & 0.06 & 0.21 & 0 & 0.20 \\
\hline & 2 & 0.68 & 0 & 0 & 1.02 & 0.59 & 0.002 & 0.87 & 0.008 & 0.19 & 0.03 \\
\hline & 3 & 153.77 & 0 & 0.23 & 811.61 & 0.12 & 0.02 & 0 & 0.52 & 0 & 1.84 \\
\hline & 4 & 143.04 & 0 & 0 & 2.16 & 0.49 & 0 & 0.03 & 0 & 0 & 0.16 \\
\hline \multirow{4}{*}{$\begin{array}{l}\text { Trabecular } \\
\text { structures }\end{array}$} & 1 & 0.64 & 1.47 & 0.04 & 0.37 & 0.19 & 0.13 & 2.99 & 0.46 & 0 & 0.22 \\
\hline & 2 & 0 & 47.95 & 0 & 0.27 & 5.24 & 0.55 & 44.77 & 0 & 0 & 4.55 \\
\hline & 3 & 0 & 0 & 0 & 12.69 & 0.83 & 0 & 0 & 0 & 0 & 0 \\
\hline & 4 & 14.12 & 0 & 0 & 0.31 & 0.26 & 0 & 0 & 53.01 & 0 & 2.19 \\
\hline \multirow{4}{*}{$\begin{array}{l}\text { Discrete groups of } \\
\text { tumor cells }\end{array}$} & 1 & 0.23 & 0 & 4.001 & 1.90 & 3.12 & 0 & 28.18 & 0.99 & 0 & 0.63 \\
\hline & 2 & 0 & 18172.53 & 0 & 1.14 & 70.62 & 0 & 0 & 0 & 0 & 53.50 \\
\hline & 3 & 0 & 0 & 0 & 27.74 & 0.63 & 0 & 0 & 0 & 0 & 0 \\
\hline & 4 & 1773.89 & 0 & 0 & 0.87 & 0.05 & 0 & 0 & 0 & 0 & 0 \\
\hline \multirow{2}{*}{$\begin{array}{l}\text { Tubular } \\
\text { structures }\end{array}$} & 3 & 0 & 0 & 0 & 0 & 28.45 & 49.93 & 0 & 0 & 0 & 0 \\
\hline & 4 & 0 & 0 & 0 & 0 & 0 & 0 & 0.16 & 0 & 0 & 0 \\
\hline
\end{tabular}

The results are presented as $\mathrm{n}$-fold differences in the target gene expression relative to ACTB1 and normal breast tissue. 
Supplementary Table 3. Expression levels of drug resistance genes in different morphological structures of breast tumors $(n=4)$

\begin{tabular}{|c|c|c|c|c|c|c|c|c|c|c|c|c|c|}
\hline & Cases & $A B C B 1$ & TAP2 & $A B C C 1$ & $A B C C 3$ & $A B C C 5$ & $A B C G 1$ & $A B C G 2$ & GSTP1 & TOP1 & TOP2A & TYMS & TUBB3 \\
\hline \multirow{4}{*}{$\begin{array}{l}\text { Solid } \\
\text { structures }\end{array}$} & 1 & 0 & 0.07 & 1.30 & 32.65 & 6.19 & 0.34 & 0 & 6.07 & 0.02 & 0 & 0.15 & 1116.15 \\
\hline & 2 & 0 & 0 & 0 & 255.06 & 1260.52 & 3.44 & 0 & 20.35 & 2.73 & 0 & 3.38 & 60.77 \\
\hline & 3 & 0 & 0.82 & 0.08 & $0.04^{*}$ & 0.07 & 0.08 & 0 & 0.0004 & 0 & 0.27 & 0.03 & 3315.15 \\
\hline & 4 & 0 & 0.04 & 1.01 & 0 & 0.18 & 29.70 & 0 & 1.86 & 0 & 19.53 & 11.49 & 1.97 \\
\hline \multirow{4}{*}{ Alveolar structures } & 1 & 0 & 0.003 & 0.30 & 4.98 & 0.03 & 0.002 & 0 & 1.46 & 0 & 0 & 1.57 & 2274.56 \\
\hline & 2 & 0 & 0.89 & 0 & 2.78 & 0.16 & 0.46 & 0 & 0 & 0.62 & 0 & 0 & 1.14 \\
\hline & 3 & 0 & 13.08 & 0.06 & $0.0003^{*}$ & 0.004 & 1.86 & 0 & 0.01 & 0.003 & 0.05 & 0.02 & 13.25 \\
\hline & 4 & 0 & 0 & 0 & 0.44 & 0.44 & 20.99 & 0 & 0.0002 & 0 & 0 & 0 & 0 \\
\hline \multirow{4}{*}{$\begin{array}{l}\text { Trabecular } \\
\text { structures }\end{array}$} & 1 & 0.12 & 507.34 & 0.001 & 71.58 & 0.004 & 5.35 & 0.002 & 5.13 & 0.61 & 0.28 & 7.97 & 1941.29 \\
\hline & 2 & 2.21 & 0 & 0 & 71.99 & 0 & 0.07 & 21.36 & 15.71 & 0.82 & 0 & 4.36 & 12.30 \\
\hline & 3 & 0 & 0.12 & 0 & 0 & 0.01 & 0.0001 & 0.06 & 0.01 & 0.02 & 0 & 0.01 & 547.60 \\
\hline & 4 & 0 & 0.48 & 0.84 & 1.32 & 0.78 & 4.02 & 0.01 & 0.002 & 8.49 & 0 & 5.58 & 1.58 \\
\hline \multirow{4}{*}{$\begin{array}{l}\text { Discrete groups of } \\
\text { tumor cells }\end{array}$} & 1 & 0 & 0 & 0.13 & 16.53 & 2.04 & 6.39 & 301.59 & 5.39 & 0 & 1110.84 & 63.71 & 3000591.96 \\
\hline & 2 & 0 & 0 & 0 & 6333.55 & 0 & 0.74 & 29.91 & 52.34 & 0.57 & 0 & 489.33 & 12626.88 \\
\hline & 3 & 0 & 0 & 0 & 0 & 0.09 & 2.64 & 0 & 0.002 & 0.0003 & 0 & 0 & 9.17 \\
\hline & 4 & 0 & 28.45 & 0 & 0 & 0.31 & 0 & 49.78 & 0.05 & 0.24 & 104.55 & 34.21 & 0.36 \\
\hline \multirow{2}{*}{$\begin{array}{l}\text { Tubular } \\
\text { structures }\end{array}$} & 3 & 0 & 0 & 0 & $0.0001^{*}$ & 0 & 0 & 0 & 0.04 & 0 & 0 & 39.98 & 24.64 \\
\hline & 4 & 0 & 0 & 0 & 0 & 0 & 44.31 & 0 & 0 & 0 & 0 & 0 & 0 \\
\hline
\end{tabular}

The results are presented as $\mathrm{n}$-fold differences in the target gene expression relative to ACTB1 and normal breast tissue.

*, expression levels are given without normalization to normal breast tissue, because $A B C C 3$ gene expression was absent in normal tissue.

Supplementary Table 4. Comparison of expression of $C D H 1, A B C G 1, A B C G 2$, and $A B C B 1$ genes with its protein expression

\begin{tabular}{|c|c|c|c|c|c|c|c|c|c|}
\hline & \multirow{2}{*}{ Cases } & \multicolumn{2}{|c|}{$\mathrm{CDH} 1$} & \multicolumn{2}{|c|}{$A B C G 1$} & \multicolumn{2}{|c|}{ ABCG2 } & \multicolumn{2}{|c|}{$A B C B 1$} \\
\hline & & qRT-PCR & IHC & qRT-PCR & IHC & qRT-PCR & IHC & qRT-PCR & IHC \\
\hline \multirow{4}{*}{$\begin{array}{l}\text { Solid } \\
\text { structures }\end{array}$} & 1 & 0.74 & 32 & 0.34 & 78 & 0 & 35 & 0 & 0 \\
\hline & 2 & 617.25 & 98 & 3.44 & 99 & 0 & 0 & 0 & 0 \\
\hline & 3 & 3.75 & 100 & 0.08 & 100 & 0 & 100 & 0 & 0 \\
\hline & 4 & 13.19 & 89 & 29.70 & 100 & 0 & 100 & 0 & 0 \\
\hline \multirow{4}{*}{$\begin{array}{l}\text { Alveolar } \\
\text { structures }\end{array}$} & 1 & 0 & 14 & 0.002 & 21 & 0 & 27 & 0 & 0 \\
\hline & 2 & 0.68 & 99 & 0.46 & 98 & 0 & 0 & 0 & 0 \\
\hline & 3 & 153.77 & 100 & 1.86 & 100 & 0 & 100 & 0 & 0 \\
\hline & 4 & 143.04 & 65 & 20.99 & 100 & 0 & 100 & 0 & 0 \\
\hline \multirow{4}{*}{$\begin{array}{l}\text { Trabecular } \\
\text { structures }\end{array}$} & 1 & 0.64 & 27 & 5.35 & 74 & 0.002 & 33 & 0.12 & 0 \\
\hline & 2 & 0 & 89 & 0.07 & 74 & 21.36 & 46 & 2.21 & 0 \\
\hline & 3 & 0 & 100 & 0.0001 & 100 & 0.06 & 100 & 0 & 0 \\
\hline & 4 & 14.12 & 78 & 4.02 & 100 & 0.01 & 100 & 0 & 0 \\
\hline \multirow{4}{*}{$\begin{array}{l}\text { Discrete groups of } \\
\text { tumor cells }\end{array}$} & 1 & 0.23 & 7 & 6.39 & 15 & 301.59 & 13 & 0 & 0 \\
\hline & 2 & 0 & 65 & 0.74 & 56 & 29.91 & 0 & 0 & 0 \\
\hline & 3 & 0 & 100 & 2.64 & 100 & 0 & 100 & 0 & 0 \\
\hline & 4 & 1773.89 & 72 & 0 & 100 & 49.78 & 100 & 0 & 0 \\
\hline \multirow{2}{*}{$\begin{array}{l}\text { Tubular } \\
\text { structures }\end{array}$} & 3 & 0 & 100 & 0 & 100 & 0 & 100 & 0 & 0 \\
\hline & 4 & 0 & 96 & 44.31 & 100 & 0 & 100 & 0 & 0 \\
\hline
\end{tabular}

qRT-PCR results are shown as $\mathrm{n}$-fold differences in the target gene expression relative to ACTB1 and normal breast tissue. IHC (immunohistochemistry) results are presented as the percentage of positively stained cells with any degree of positive marker expression in different parts of section (1000 cells in 10 fields of view, 400x magnification), corresponding to different morphological structures. 